Revista Brasil. Bot., V.25, n.3, p.331-338, set. 2002

\title{
Taxa de cruzamento e sistema reprodutivo de uma população natural de Copaifera langsdorffii Desf. na região de Lavras (MG) por meio de isoenzimas ${ }^{1}$
}

\author{
ALESSANDRO F. OLIVEIRA², DULCINÉIA DE CARVALHO ${ }^{2,3}$ e SEBASTIÃO C.S. ROSADO²
}

(recebido: 18 de abril de 2001; aceito: 29 de maio de 2002)

\begin{abstract}
Outcrossing rate and mating system of a natural population of Copaifera langsdorffii Desf. in the region of Lavras, MG, starting from isozyme). A natural population of the tree species Copaifera langsdorffii Desf., commonly found in Brazil, was investigated by isozyme electrophoresis, aiming to determine the outcrossing rate and mating system. The population sampled is located along a stretch of the river Capivari in an area of preservation (Riparian Forest), between the towns of Lavras and Itumirim, south of Minas Gerais State, Brazil. Samples of leaf tissue were taken from 20 adult individuals and from 400 progenies for isozyme analysis. Five enzymatic systems were evaluated in adults (24 alleles average) and progenies (29 total alleles). The mating system of this population was approached by the Hardy-Weinberg equilibrium test (HWE) where it was found that most loci of the adult individuals is in the ratios of the HWE and most loci of the progenies is out of the it. The estimate of the average multilocus $\left(t_{m}\right)$ and unilocus outcrossing rate $\left(t_{S}\right)$ was respectively 0.917 and 0.877 , pointing out the existence of self-fertilization $(8 \%)$ in the population studied. The results obtained by isozymes analyses indicated also that the species Copaifera langsdorffii is predominantly alogamous. The population has relatively high genetic variation making this population of $C$. langsdorffii a valuable source for genetic conservation. The minimum area size estimated for the in situ conservation was 5.0 ha.
\end{abstract}

RESUMO - (Taxa de cruzamento e sistema reprodutivo de uma população natural de Copaifera langsdorffii Desf. na região de Lavras, MG, por meio de isoenzimas). Uma população natural de Copaifera langsdorffii Desf., espécie arbórea comumente encontrada no Brasil, foi estudada por meio da eletroforese de isoenzimas, visando determinar a taxa de cruzamento e o sistema reprodutivo. A população amostrada localiza-se ao longo de um trecho do rio Capivari, em uma área de preservação permanente (floresta ciliar), entre os municípios de Lavras e Itumirim, sul do Estado de Minas Gerais, Brasil. Foram amostrados tecidos foliares de 20 indivíduos adultos da população e 400 indivíduos jovens (progênies) procedentes de sementes coletadas de 20 matrizes na população. Cinco sistemas enzimáticos revelaram 24 e 29 alelos totais para os indivíduos adultos e progênies, distribuídos em 12 locos. O sistema reprodutivo desta população foi inicialmente abordado pelo teste de Equilíbrio de HardWeinberg (EHW), tendo-se verificado que a maioria dos locos dos indivíduos adultos encontra-se nas proporções do EHW e a maioria dos locos das progênies encontra-se fora do EHW. A estimativa da taxa de cruzamento multilocos $\left(t_{m}\right)$ e unilocos $\left(t_{S}\right)$ média foi, respectivamente 0,917 e 0,877 indicando a existência de autofecundação (8\%) na população estudada. Os resultados obtidos indicaram também que a espécie Copaifera langsdorffii é de reprodução mista predominantemente alógama. A população estudada mostrou-se potencial para fins de conservação in situ. A área mínima estimada para conservação in situ foi de 5,0 hectares.

Key words - Copaifera langsdorffii, isozymes, Hardy-Weinberg Equilibrium

\section{Introdução}

Em populações naturais de espécies arbóreas, principalmente tropicais, existem poucas informações com relação ao sistema de cruzamentos. O conhecimento dos métodos reprodutivos é de extrema importância para compreender os padrões de fluxo gênico e a diferenciação genética entre e dentro de

1. Parte da dissertação de mestrado de Alessandro Fabiano de Oliveira.

2. Universidade Federal de Lavras, Departamento de Ciências Florestais, Caixa Postal 37, 37200-000 Lavras, MG, Brasil.

3._Autor para correspondência: dulce@ufla.br populações (Bawa 1974, Clegg 1980, Hamrick 1989). $\mathrm{O}$ estudo do sistema reprodutivo pode fornecer informações importantes sobre os padrões de cruzamentos, a dinâmica dos processos microevolucionários e quais as melhores formas para a conservação e manejo dessas espécies.

Uma das formas de se estudar o sistema reprodutivo é utilizar marcadores genéticos, pois além de quantificar o processo de transmissão de genes entre plantas, eles descrevem a transmissão de genes entre gerações (Clegg 1980). As análises da variação isoenzimática têm se expandido em pesquisas de genética florestal. As principais aplicações destas técnicas têm sido na investigação dos padrões de variação genética 
(Lundkvist \& Rudin 1977) e dos sistemas de cruzamentos (Brown et al. 1975, Shaw \& Brown 1982). Estas aplicações aumentam o conhecimento da estrutura genética em povoamentos naturais, aumentando a eficiência do melhoramento e dos esforços de conservação de genes de árvores ameaçadas de extinção.

No Brasil, várias pesquisas utilizando marcadores isoenzimáticos têm sido realizadas com espécies arbóreas nativas (De Paiva et al. 1994, Reis 1996, Seoane et al. 1998, Lepsch-Cunha et al. 1999, Reis et al. 1999). Dentre estas espécies, a Copaifera langsdorffii Desf. (Caesalpinaceae), conhecida vulgarmente como óleo copaíba ou simplesmente copaíba (Carvalho 1994), se destaca por sua importância sócio-econômica, ampla plasticidade fenotípica e usos. Apesar de sua ampla distribuição, esta espécie encontra- se atualmente na lista das espécies ameaçadas de extinção, sendo a sua conservação genética feita por populações bases ex situ no estado de São Paulo (Siqueira \& Nogueira 1992).

O presente trabalho foi realizado com o intuito de gerar conhecimentos sobre o sistema reprodutivo e a taxa de cruzamento de uma população natural de Copaifera langsdorffii. Estes conhecimentos constituem-se em instrumento de grande valor para o delineamento de programas de conservação genética e manejo dessa espécie.

\section{Material e métodos}

O presente estudo foi realizado em um fragmento de floresta ciliar localizado à margem do rio Capivari, afluente do rio Grande, entre os municípios de Lavras e Itumirim, no estado de Minas Gerais $\left(21^{\circ} 18^{\prime} 00^{\prime \prime} \mathrm{S}\right.$ e $44^{\circ} 53^{\prime} 30^{\prime \prime}$ W, e a uma altitude de aproximadamente $918 \mathrm{~m}$ ), com uma área que abrange cerca de 14,0 hectares.

A amostragem dos indivíduos foi aleatória, abrangendo toda a área. Foram efetuadas coletas de material vegetal, coletando-se folhas de 33 indivíduos reprodutivamente ativos na população. Sementes de 20 árvores adultas para a observação de suas progênies foram coletadas e plantadas no viveiro florestal do Departamento de Ciências Florestais da Universidade Federal de Lavras (DCF-UFLA), LavrasMG, contendo 20 plântulas de cada árvore adulta, totalizando 400 plântulas.

O método de caracterização genética da espécie usado neste trabalho foi a eletroforese de isoenzimas, seguindo as técnicas mais utilizadas, particularmente a metodologia descrita por Alfenas (1998). Todo o trabalho foi realizado no Laboratório de Melhoramento Florestal e Biologia Molecular do DCF-UFLA.

As amostras de tecido foliar foram limpas e maceradas com areia lavada, 5 mg de PVP-P e solução tampão de extração (tampão n. 1 descrito em Alfenas (1998)). A extração de enzimas foi realizada em bastões e placas de porcelana que foram mantidas resfriadas antes e durante o processo.

A eletroforese de isoenzimas utilizada foi a vertical, conduzida em meio suporte de gel de poliacrilamida no sistema descontínuo, sendo o gel de concentração a $4,0 \%$ e o gel de separação a 12,5\%. Cada gel acondicionava amostras de 20 indivíduos. A corrente elétrica inicial foi de $10 \mathrm{~mA}$ para cada, sendo o tempo médio de corrida de 3 h e $30 \mathrm{~min}$. Foram testados 21 sistemas enzimáticos, dos quais $\alpha$-EST (alfa-esterase, EC 3.1.1.1), ACP (fosfatase ácida, EC 3.1.3.2), GOT (glutamato-oxaloacetato transaminase, EC 2.6.1.1), MDH (malato desidrogenase, EC 1.1.1.37), PO (peroxidase, EC 1.11.1.7) foram os empregados, pois apresentaram polimorfismo e resolução passível de interpretação. As revelações dos géis foram baseadas na metodologia descrita por Alfenas (1998). A interpretação de cada sistema enzimático foi realizada seguindo os padrões descritos nos trabalhos de Weeden (1983), Soltis \& Soltis (1989), Kephart (1990) e Alfenas (1998).

O sistema reprodutivo foi inicialmente abordado pelo teste de Equilíbrio de Hardy-Weinberg (EHW) na população. Foram estimadas as taxas de cruzamentos, unilocos e multilocos. Com o objetivo de testar a adequação dos dados ao modelo multilocos, foram comparadas as freqüências alélicas dos óvulos e do pólen, óvulos e indivíduos adultos e entre as progênies, para verificar se o pólen fornecido para a formação das plântulas foi homogêneo nos cruzamentos. A aderência dos dados da população ao EHW foi testada utilizando o programa BIOSYS-1 de Swoford \& Selander (1989). Este programa calcula o desvio da distribuição dos genótipos observados em relação ao esperado segundo o EHW.

A taxa de cruzamento foi caracterizada a partir das taxas unilocos $\left(t_{s}\right)$ e multilocos $\left(t_{m}\right)$, através de estimativas de máxima verossimilhança (Ritland \& El-Kassaby 1985, Ritland \& Jain 1981), com a utilização do programa MLTR - Multilocus Mating System Program - de Ritland (1997), baseado no modelo de cruzamento misto de Clegg (1980) e de Ritland \& Jain (1981). Este modelo assume que as plântulas resultam de uma mistura de cruzamentos aleatórios e autofecundação. O programa permite obter $t_{s}$ e $t_{m}$ para a população, bem como as freqüências alélicas do óvulo e do pólen, pelo método de máxima verossimilhança, utilizando o algoritmo EM. Para estimar o erro padrão das estimativas $t_{s}$ e $t_{m}$, para a população, o programa utiliza o método "bootstrap", no qual a unidade de reamostragem são as plantas dentro das progênies. Utilizaram-se 1.000 reamostragens dentro das progênies, com base em Ritland (1997).

O tamanho efetivo populacional $\left(N_{e}\right)$ foi obtido a partir do componente de variância da freqüência alélica média, para progênies e adultos, conforme Vencovsky (1992). Essas expressões podem servir para orientar estratégias de amostragem de germoplasma ou mesmo visando a coleta de 
sementes para fins de reflorestamentos, em função da grandeza observada dos componentes da variância.

\section{Resultados e Discussão}

As características apresentadas pelos sistemas enzimáticos para os tecidos foliares de Copaifera langsdorffii Desf. foram:

MDH apresentou dois locos. O loco 1 teve três alelos na população adulta e nas progênies e o loco 2 apresentou dois alelos em ambas;

$\alpha$-EST apresentou dois locos passíveis de interpretação para a população estudada. O primeiro $(\alpha$-Est-1) e o segundo ( $\alpha$-Est-2) apresentaram-se polimórficos, com três alelos na população adulta e também nas progênies; $\mathrm{PO}$ apresentou dois locos, ambos polimórficos. $\mathrm{Na}$ população de adultos e progênies, ocorreram três alelos no loco um e dois alelos no loco dois;

ACP apresentou quatro locos, sendo monomórfica nos locos um e quatro, e polimórfica para os locos dois e três, verificando-se dois alelos em cada loco. Para as progênies, foi observado um alto índice de polimorfismo, com dois alelos no loco 1e 2, e três alelos no loco 3;

GOT apresentou um loco para a população adulta e dois locos para as progênies onde foram observados três alelos no loco 2 .

As freqüências alélicas (tabela 1) variaram na população desde uma completa fixação de alelos dos locos Acp-1 e Acp-4 nos adultos e Acp-1 nas progênies, até frequiências muito baixas, como no caso do alelo 2 no loco Got-1 (0,024 ) na população; alelo 3 nos locos Est-1 (0,007), Est-2 (0,031), Acp-3 (0,025), Got-2 $(0,026)$, Prx-1 $(0,054)$, Mdh-1 $(0,024)$; e alelo 2 nos locos Acp-1 (0,039), Got-1 $(0,013)$ nas progênies. A presença do loco Got-2 foi exclusiva nas progênies, assim como alguns alelos que só foram observados em alguns indivíduos da população, tais como alelo 2 no loco Got-1 e alelo 3 no loco Mdh-1 (adultos e suas progênies).

Comparando-se as freqüências alélicas da população de adultos com as das progênies, verificouse que não existem muitas diferenças entre elas, sugerindo, assim, a existência de equilíbrio entre gerações. De modo geral, o alelo mais comum nos adultos também foi o mais comum nas progênies. Observa-se, também, que as progênies apresentaram dois alelos (alelo 2 no loco Acp-1 e alelo 3 no loco Acp-3) raros, ausentes nos adultos. Isto pode ter ocorrido por dois fatores: efeito de deriva genética variação amostral nos indivíduos adultos, ou seja, os
33 indivíduos adultos amostrados não foram suficientes para representar a frequiência alélica de toda a população e devido ao fluxo gênico advindo de outras populações de $C$. langsdorffii. Esta última hipótese parece bem provável para o caso do alelo 2 no loco Acp-1, o qual é fixado na população da mata ciliar. Oscilações nas freqüências alélicas, perdas e fixação de alelos, podem ser indicativo de deriva genética ou de seleção. As oscilações se desenvolvem por meio de processos aleatórios, quando não existem mecanismos de seleção natural. No caso da seleção, o efeito poderia ser tanto de natureza direta, uma vez que as aloenzimas participam de rotas metabólicas que afetam características sujeitas à seleção, como de natureza indireta, se os locos aloenzimáticos estiverem ligados a genes controladores daquelas características. A análise das frequiências alélicas é de grande importância, pois pode refletir melhor os efeitos estocásticos do que a maioria dos parâmetros utilizados no estudo de genética de populações, uma vez que tais parâmetros não refletem diretamente freqüências alélicas eventualmente muito baixas.

O Equilíbrio de Hardy-Weinberg (EHW) é baseado em premissas de cruzamentos aleatórios, ausência de mutação, migração, deriva genética, seleção e tamanho infinito das populações (Metter \& Gregg 1973). Se houver algum desvio das frequiências observadas em relação às frequiências esperadas no equilíbrio, este é devido a alguma violação dessas premissas. Devido à pressuposição de cruzamentos aleatórios, a avaliação da existência de EHW nas populações pode ser uma forma inicial de abordar o sistema reprodutivo das espécies (Reis 1996). Os indivíduos adultos e as plântulas da população de $C$. langsdorffii foram submetidos ao teste de EHW (tabela 2). O teste exato de Fisher (P) foi priorizado, pois o número de genótipos esperados (ne) foi inferior a 1,00, pelo teste de quiquadrado $\left(X^{2}\right)$. Os testes exatos são geralmente usados para tamanhos amostrais pequenos, quando há maior chance de ter números esperados pequenos no teste $X^{2}$ (Weir 1996). Conforme este autor, mesmo em amostras moderadamente grandes, a existência de alelos raros no loco resulta em números esperados pequenos; nesse caso, os testes exatos são preferíveis. Segundo Gomes (1990), o teste $X^{2}$ não deve ser usado quando a frequiência esperada mínima for inferior a 1 e quando não mais de $20 \%$ das frequiências esperadas forem inferiores à 5 , pois o valor do $X^{2}$ resultante será viesado e não pode ser legitimamente comparado com os valores na tabela de distribuição (Zar 1984). Quando essas regras não se aplicam, o teste exato de Fisher deve ser 
Tabela 1. Freqüências alélicas e tamanho da amostra (n) em 12 locos aloenzimáticos de uma população natural de Copaifera langsdorffii Desf.

\begin{tabular}{|c|c|c|c|}
\hline Locos & Alelos & Adultos & Progênies \\
\hline \multirow[t]{4}{*}{$\alpha$-esterase 1} & 1 & 0,529 & 0,362 \\
\hline & 2 & 0,441 & 0,631 \\
\hline & 3 & 0,029 & 0,007 \\
\hline & $\mathrm{n}$ & 17 & 290 \\
\hline \multirow[t]{5}{*}{$\alpha$-esterase 2} & 1 & 0,464 & 0,457 \\
\hline & 2 & 0,286 & 0,512 \\
\hline & 3 & 0,250 & 0,031 \\
\hline & 4 & 0,000 & 0,000 \\
\hline & $\mathrm{n}$ & 28 & 383 \\
\hline \multirow[t]{3}{*}{ fosfatase ácida 1} & 1 & 1,000 & 0,961 \\
\hline & 2 & 0,000 & 0,039 \\
\hline & $\mathrm{n}$ & 13 & 382 \\
\hline \multirow[t]{4}{*}{ fosfatase ácida 2} & 1 & 0,654 & 0,658 \\
\hline & 2 & 0,346 & 0,342 \\
\hline & 3 & 0,000 & 0,000 \\
\hline & $\mathrm{n}$ & 13 & 360 \\
\hline \multirow[t]{4}{*}{ fosfatase ácida 3} & 1 & 0,769 & 0,676 \\
\hline & 2 & 0,231 & 0,299 \\
\hline & 3 & - & 0,025 \\
\hline & $\mathrm{n}$ & 13 & 276 \\
\hline \multirow[t]{3}{*}{ fosfatase ácida 4} & 1 & 1,000 & 1,000 \\
\hline & 2 & - & - \\
\hline & $\mathrm{n}$ & 13 & 395 \\
\hline \multirow[t]{3}{*}{ Glutamato oxaloacetato transaminase 1} & 1 & 0,976 & 0,987 \\
\hline & 2 & 0,024 & 0,013 \\
\hline & $\mathrm{n}$ & 21 & 356 \\
\hline \multirow[t]{4}{*}{ Glutamato oxaloacetato transaminase 2} & 1 & - & 0,777 \\
\hline & 2 & - & 0,196 \\
\hline & 3 & - & 0,026 \\
\hline & $\mathrm{n}$ & - & 191 \\
\hline \multirow[t]{5}{*}{ Peroxidase 1} & 1 & 0,485 & 0,478 \\
\hline & 2 & 0,409 & 0,468 \\
\hline & 3 & 0,106 & 0,054 \\
\hline & 4 & 0,000 & 0,000 \\
\hline & $\mathrm{n}$ & 33 & 231 \\
\hline \multirow[t]{4}{*}{ Peroxidase 2} & 1 & 0,577 & 0,556 \\
\hline & 2 & 0,423 & 0,444 \\
\hline & 3 & 0,000 & 0,000 \\
\hline & $\mathrm{n}$ & 13 & 360 \\
\hline \multirow[t]{4}{*}{ Malato desidrogenase 1} & 1 & 0,464 & 0,564 \\
\hline & 2 & 0,304 & 0,412 \\
\hline & 3 & 0,232 & 0,024 \\
\hline & $\mathrm{n}$ & 28 & 373 \\
\hline \multirow[t]{4}{*}{ Malato desidrogenase 2} & 1 & 0,500 & 0,547 \\
\hline & 2 & 0,500 & 0,453 \\
\hline & 3 & 0,000 & 0,000 \\
\hline & $\mathrm{n}$ & 13 & 320 \\
\hline Total de Alelos & 35 & 24 & 29 \\
\hline
\end{tabular}


empregado por ser menos restritivo em relação às frequiências esperadas (Siegel 1956). Este teste aplicado a ambas, populações adultas e progênies, evidenciou desvios significativos do modelo em $33,3 \%$ e $66,7 \%$, respectivamente. A não aderência das frequiências gênicas foi devida ao déficit de heterozigotos observados em relação ao número de heterozigotos esperados pelo modelo. No entanto, verifica-se que a maioria dos locos dos indivíduos adultos encontra-se nas proporções do EHW, sugerindo que as populações foram geradas por cruzamentos aleatórios. Entretanto, verifica-se que as progênies estão fora do EHW para a maioria dos locos (tabela 2).

Neste caso, têm-se indivíduos adultos em EHW gerando progênies fora do EHW, devido a desvios de cruzamentos aleatórios e/ou algum fator evolutivo. Por exemplo, já foram detectados indícios de migração (alelos presentes nas progênies e ausentes nos adultos), seleção a favor dos heterozigotos $(f=-0,203)$ e que as progênies não são exclusivamente de meio irmãos, logo os cruzamentos não foram totalmente aleatórios.

A tabela 3 mostra os valores da taxa de cruzamento por progênie $(t)$. Diferenças positivas entre $t_{m}$ e $t_{s}$ $\left(t_{m}-t_{s}\right)$ permitem obter a taxa de cruzamento entre aparentados (Shaw \& Allard 1982, Ritland \& El Kassaby 1985, Ritland 1990) e diferenças positivas entre $t_{m}$ e $1\left(1-t_{m}\right)$ permitem obter a taxa de autofecundação $(s)$ na população (Ritland 1990).

As médias de $t_{m}, t_{s}, t_{m}-t_{s}$ e $s$, e seus respectivos desvios padrão em parênteses, foram 0,917 $(0,041)$,
0,877 (0,030), $0,040(0,023)$ e 0,083 . O modelo multilocos permite obter a proporção de cruzamentos endogâmicos devido ao fato de $t_{s}$ ser obtida separadamente, loco a loco; portanto, através de menos informações sobre freqüências gênicas de pólen e óvulos do que da estimativa multilocos que considera simultaneamente vários locos no cálculo da taxa de cruzamento. A taxa multilocos tem mais recursos para separar sementes originadas de cruzamentos da autofecundação, visto que os casos duvidosos de um loco são esclarecidos por outros locos. A taxa unilocos confunde, muitas vezes, cruzamentos entre aparentados com autofecundação e/ ou apomixia; nestes casos, subestima a taxa de cruzamento e superestima a taxa de autofecundação.

A estimativa de $t_{m}$ foi obtida a partir da avaliação das 20 progênies (tabela 3 ). Na média, a $t_{m}$ estimada foi de $0,917(0,041)$, a diferença entre $t_{m}$ e $t_{s}$ foi 0,040 e a taxa de autofecundação $(s)$ foi 0,083 . Assim, neste ciclo reprodutivo, $91,7 \%$ das plântulas foram geradas por cruzamentos, sendo $87,7 \%$ entre indivíduos não aparentados, 4,0\% entre aparentados e $8,3 \%$ por autofecundação. Pode-se, desta forma, considerar Copaifera langsdorffii como de reprodução mista, predominantemente alógama. Estes valores estão próximos da média encontrada para as angiospermas arbóreas tropicais (Moraes 1997).

A $t$ estimada por progênie variou de 0,00 a 1,00 . Esta discrepância nas taxas de cruzamentos individuais deve estar associada ao assincronismo na floração masculina e feminina, dado que as árvores não estão

Tabela 2. Probabilidades do teste exato de Fisher para hipótese do Equilíbrio de Hardy-Weinberg, para a população adulta e a progênie de Copaifera langsdorffii.

Loco

$\mathrm{P}$ (Fisher)

\begin{tabular}{lcc} 
& Adultos & Progênies \\
\cline { 2 - 3 }$\alpha$-esterase 1 & $1,000^{\mathrm{ns}}$ & $1.000^{\mathrm{ns}}$ \\
$\alpha$-esterase 2 & $0,000^{* *}$ & $0,004^{* *}$ \\
fosfatase ácida 1 & - & $0,000^{* *}$ \\
fosfatase ácida 2 & $0,578^{\mathrm{ns}}$ & $0,001^{* *}$ \\
fosfatase ácida 3 & $1,000^{\mathrm{ns}}$ & $0,029^{*}$ \\
fosfatase ácida 4 & - & $1.000^{\mathrm{ns}}$ \\
Glutamato oxaloacetato transaminase 1 & $1,000^{\mathrm{ns}}$ & $1,000^{\mathrm{ns}}$ \\
Glutamato oxaloacetato transaminase 2 & $-\bar{x}^{* *}$ & $0,000^{* *}$ \\
Peroxidase 1 & $0,002^{* *}$ & $0,065^{\mathrm{ns}}$ \\
Peroxidase 2 & $0,275^{\mathrm{ns}}$ & $0,025^{*}$ \\
Malato desidrogenase 1 & $0,006^{* *}$ & $0,001^{* *}$ \\
Malato desidrogenase 2 & $0,300^{\mathrm{ns}}$ & $0,000^{* *}$
\end{tabular}

${ }^{*} \mathrm{P}<0,05 \quad{ }^{* *} \mathrm{P}<0,01 \quad{ }^{\mathrm{ns}}=$ não significativo. 
Tabela 3. Estimativas das taxas de cruzamento por progênie e de autofecundação na população $(s)$ de Copaifera langsdorffii Desf.

\begin{tabular}{lll}
\hline Progênie & $t$ & $s$ \\
\hline P 01 & $0,78(0,12)$ & 0,22 \\
P 02 & $1,00(0,02)$ & 0,00 \\
P 03 & $0,95(0,06)$ & 0,05 \\
P 04 & $0,92(0,06)$ & 0,08 \\
P 05 & $0,91(0,07)$ & 0,09 \\
P 06 & $0,78(0,11)$ & 0,22 \\
P 07 & $0,76(0,17)$ & 0,24 \\
P 08 & $1,00(0,00)$ & 0,00 \\
P 09 & $0,31(0,11)$ & 0,69 \\
P 10 & $0,98(0,06)$ & 0,02 \\
P 11 & $0,00(0,00)$ & 1,00 \\
P 12 & $0,93(0,06)$ & 0,07 \\
P 13 & $0,50(0,19)$ & 0,50 \\
P 14 & $0,92(0,00)$ & 0,08 \\
P 15 & $1,00(0,14)$ & 0,00 \\
P 16 & $0,91(0,14)$ & 0,09 \\
P 17 & $0,99(0,04)$ & 0,01 \\
P 18 & $0,99(0,04)$ & 0,01 \\
P 19 & $0,05(0,08)$ & 0,95 \\
P 20 & $1,00(0,00)$ & 0,00 \\
\hline
\end{tabular}

isoladas, ou ainda devido ao comportamento dos polinizadores. Provavelmente as progênies de número P09, P11, P13 e P19, que apresentaram um baixo valor de $t$, floresceram no início ou no fim do pico da florada masculina da população, fase em que provavelmente havia pouco ou nenhum pólen disponível para os cruzamentos, o que possivelmente possibilitou a autofecundação.

A partir da estimativa de $N_{e}$ (tabela 4), para plantas adultas, pode-se afirmar que os indivíduos (n) amostrados na população representam, geneticamente, 41,5 plantas, respectivamente, de uma população panmítica ideal. O tamanho efetivo foi superior ao número de indivíduos. Estes resultados estão de acordo com os índices de fixação detectados, ou seja, não há endogamia nas plantas adultas desta população. Esta superioridade decorreu da alta heterozigosidade detectada nesta geração.

A estimativa do tamanho efetivo obtido com as progênies foi bastante baixa em relação ao número de indivíduos (tabela 4), o que é naturalmente esperado devido ao parentesco existente entre as plântulas das progênies. Esta estimativa mostra que 396 plântulas analisadas da população da mata ciliar correspondem a
56 indivíduos de uma população panmítica ideal.

O valor máximo assumido por $N_{e}$ para amostras de tamanho infinito, ou na ordem de centenas, em espécies alógamas é $4 n$, onde $n$ é o número de matrizes; assim, $N_{e / \text { matriz }}$ poderia atingir o valor 4 . O $N_{e / \text { matriz }}$, foi médio, 2,80 (55,93/20). Este valor decorre do tamanho finito da prole da matriz, 20 plântulas. Por sua vez, o $N_{e}$ poderia atingir o valor máximo de $80(4 \times 20)$. O $N_{e}$ obtido foi de 55,93, que corresponde a $69,91 \%$ do máximo, revelando a existência de homozigose no conjunto das progênies, em concordância aos índices de fixação de Wright $\left(f_{\text {adultos }}=-0,203\right.$ e $f_{\text {progênies }}$ $=-0,033)$.

Vencovsky (1987) sugere, para aumentar o $N_{e}$, tanto para a coleta de sementes como para a preservação de germoplasma, que se processe o controle gamético feminino através da colheita de um número aproximadamente igual de sementes de cada matriz. Tal prática reduz o efeito da deriva genética ou, em termos quantitativos, reduz a variância do número de gametas fornecidos pelas plantas genitoras, aumentando o $N_{e}$ ou, em outros termos, a representatividade genética do material. Na atividade de coleta de sementes, o ideal é que se procure sempre reunir descendentes, como sementes, de um maior número possível de plantas genitoras, e de preferência um número igual ou aproximadamente igual de sementes de cada uma. De acordo com Oliveira (2000), para Copaifera langsdorffii, o ideal é que se colete sementes, em igual número, de pelo menos 25 matrizes, aleatoriamente, nas populações. Esta estratégia garantiria a manutenção da variabilidade genética no conjunto das sementes. A recuperação de áreas degradadas com sementes coletadas a partir destes princípios dará origem a populações com alto potencial evolutivo, dada a possibilidade de infinitas novas recombinações genotípicas que, por sua vez, aumentarão a adaptabilidade da espécie ao ambiente, a possíveis mudanças ambientais futuras e à colonização de novas áreas.

Tabela 4. Tamanho efetivo $\left(N_{e}\right)$ e número matrizes avaliadas (n) de uma população natural de Copaifera langsdorffii Desf. obtidos de dados de indivíduos adultos e de progênie.

\begin{tabular}{lllr}
\hline População & $N_{e}$ & $N_{e / \text { matriz }}$ & $n$ \\
\hline Adultos & 41,5 & - & 20 \\
Progênies & 55,9 & 2,80 & 396 \\
\hline
\end{tabular}


Para fins de conservação in situ, a população estudada mostrou-se potencial considerando a heterozigosidade observada, a baixa endogamia nos adultos e os indícios de seleção para heterozigotos entre a fase de plântula e a fase adulta. Para se obter a área mínima viável para a conservação in situ, tomando-se como 50 o número mínimo de indivíduos para esta prática (Frankel \& Soulé 1981) e sendo a relação $N_{e} / \mathrm{n}$ da população da mata ciliar igual a 2,08 (41,5/20), e o número médio de plantas reprodutivas por hectare igual a 48, estimado a partir dos dados de Souza (2001), supõe-se que estas poderão ser conservadas em áreas de 0,50 ha $[50 /(48 \times 2,08)]$, sem que ocorra o perigo da perda de alelos raros a curto prazo. Entretanto, Frankel \& Soulé (1981) sugerem 500 ou mais indivíduos para a conservação de uma população ideal (com cruzamentos aleatórios, iguais proporções de indivíduos de ambos os sexos, sem flutuações na população, sem sobreposição de gerações e distribuição aleatória das progênies). Neste caso, a área de floresta requerida para a conservação de Copaifera langsdorffii seria de 5,0 ha, podendo ser considerada uma mata pequena. Este resultado decorre da alta densidade de indivíduos na população e mostra que, para o caso da conservação de ecossistemas florestais, o ideal é que a estimativa da área viável seja realizada a partir das espécies raras (menos de quatro indivíduos por hectare) (Hamrick \& Murawski 1991), visto que estas requerem muito espaço para a sua manutenção. Então, utilizando espécies raras na determinação da área mínima viável para a conservação, um grande número de espécies comuns, como a C. langsdorffii, será preservado indiretamente, visto que estas requerem menos área para a sua manutenção.

\section{Referências bibliográficas}

ALFENAS, A.C. 1998. Eletroforese de isoenzimas e proteínas afins - fundamentos e aplicações em plantas e microrganismos. Universidade Federal de Viçosa, Viçosa.

BAWA, K.S. 1974. Breeding systems of tree species for a lowland tropical community. Evolution 28:85-92.

BROWN, A.H.D., MATHESON, A.C. \& ELDRIDGE, K.G. 1975. Estimation of the mating system for Eucalyptus obliqtia L' Herit. using allozyme polymorphism. Australian Journal of Botany 23:931-949.

CARVALHO, P.E.R. 1994. Espécies florestais brasileiras: recomendações silviculturais, potencialidades e uso de madeira. Embrapa-CNPF, Brasília.

CLEGG, M.T. 1980. Measuring plant mating systems. BioScience 30:814-818.
DEPAIVA, J.R., KAGEYAMA, P.Y. \& VENCOVSKY, R. 1994. Genetics of rubber tree (Hevea brasiliensis (Willd. ex A. Juss.) Muell. Arg. 2. Mating system. Silvae Genetica 34:373-376.

FRANKEL, O.H. \& SOULÉ, M.E. 1981. Conservation and evolution. Cambridge University Press, Cambridge.

GOMES, F.P. 1990. Curso de estatística experimental. 13 ed. Nobel, São Paulo.

HAMRICK, J.L. 1989. Isozymes and analysis of genetic structure in plant populations. In Isozymes and the analysis of genetic structure in plant populations. (D.E. Soltis \& P. Soltis, eds). Chapman and Hall, New York, p.87-105.

HAMRICK, J.L. \& MURAWSKI, D.A. 1991. Levels of allozyme diversity in population of uncommon neotropical tree species. Journal of Tropical Ecology 7:395-399.

KEPHART, S.R. 1990. Starch gel electroforesis of plant isozyme: a comparative analysis of techniques. American Journal of Botany 77:693-712.

LEPSCH-CUNHA, N., KAGEYMA, P. Y. \& VENCOVSKY, R. 1999. Genetic diversity of Couratari multiflora and Couratari guianenis (Lecythidaceae): consequences of two types of rarity in central Amazônia. Biodiversity and Conservation 8:1205-1218.

LUNDKWIST, K. \& RUDIN, D. 1977. Genetic variation in eleven populations of Picea abies as determined by isozyme analysis. Hereditas 85:67-74.

METTER, I.E. \& GREGG, T.G. 1973. Genética de populações e evolução. Polígono, São Paulo.

MORAES, P.L.R. 1997. Estrutura genética de populações de Cryptocarya moschata Nees \& Martius ex Nees (Lauraceae). Tese de doutorado, Universidade Estadual Paulista "Júlio de Mesquita Filho", Rio Claro.

OLIVEIRA, A.F. 2000. Estrutura genética de populações naturais de Copaifera langsdorffii Desf. a partir de isoenzimas. Dissertação de mestrado, Universidade Federal de Lavras, Lavras.

REIS, M.S. 1996. Distribuição e dinâmica da variabilidade genética em populações naturais de palmiteiro (Euterpe edulis Martius). Tese de doutorado, Escola Superior de Agricultura "Luiz de Queiroz", Piracicaba.

REIS, M.S., MONTEIRO, R. \& VENCOVSKY, R. 1999. Conservação genética de populações de Cryptocarya moschata Nees (Lauraceae) na Mata Atlântica do estado de São Paulo. Revista Brasileira de Botânica 22:237-248.

RITLAND, K. 1990. A series of FORTRAN computer programs for estimating plant mating systems. Journal of Heredity 81:235-237.

RITLAND, K. 1997. Multilocus mating system program. MLTR. Version 1.1. Department of Botany, University of Toronto, Toronto.

RITLAND, K. \& EL-KASSABY, Y.A. 1985. The nature of inbreeding in a seed orchard of Douglas Fir as shown by an efficient multilocus model. Theoretical and Applied Genetics 71:371-384. 
RITLAND, K. \& JAIN, S. 1981. S. A model for the estimation of outcrossing rate and gene frequency using independent loci. Hereditary 47:35-52.

SEOANE, C.E.S., KAGEYAMA, P.Y. \& SEBBENN, A.M. 2000. Efeitos da fragmentação florestal na estrutura genética de populações de Esenbeckia leiocarpa Engl. (Guarantã). Scientia Forestalis 57:123-139.

SHAW, D.V. \& ALLARD, R.W. 1982. Estimation of outcrossing rates in Douglas-Fir using isozyme markers. Theoretical and Applied Genetics 62:113-120.

SIEGEL, S. 1956. Nonparametric statistics for the behavioral sciences. McGraw-Hill, New York.

SIQUEIRA, A.C.M.F. \& NOGUEIRA, J.C.B. 1992. Essências brasileiras e sua conservação genética no Instituto Florestal de São Paulo. In Anais do II Congresso Nacional sobre Essências Nativas (A.C. Covalli, coord.) Revista do Instituto Florestal v.4, p.1187.

SOLTIS, D.E. \& SOLTIS, P.S. 1989. Isozymes in plant biology. Discorides Press, Portland.
SOUZA, J.S. 2001. Análise das variações florísticas e estruturais da comunidade arbórea de um fragmento de floresta semidecídua às margens do Rio Capivari, Lavras-MG. Dissertação de mestrado, Universidade Federal de Lavras, Lavras.

SWOFFORD, D.L. \& SELANDER R.B. 1989. BIOSYS-1: A computer program for the analysis of allelic variation in population genetics and biochemical systematics. Release 1.7. Natural History Survey, Illinois.

VENCOVSKY, R. 1987. Tamanho efetivo populacional na coleta e preservação de germoplasma de espécies alógamas. Revista do Ipef 35:79-84.

VENCOVSKY, R. 1992. Análise da variância de frequiências alélicas. Revista Brasileira de Genética 15(1):53-60.

WEEDEN, N.F. 1983. Evolution of plant isozyme. In Isozymes in plant genetics and breeding (S.D Tanksley \& T.J. Orton, eds.). Elsevier Science, Amsterdam, p. 175-205.

WEIR, B.S. Genetic data analysis II. 1996. Methods for discrete population genetic data. Sinauer Associates, Sunderland.

ZAR, J.H. 1984. Biostatistical analysis. $2^{\text {nd }}$ ed. Prentice-Hall, Englewood Cliffs. 